\title{
基于 IT 治理的高校信息化管理框架设计研究
}

郝文英 ${ }^{1}$ 李学龙 ${ }^{2}$

1 北京物资学院 2 北京第二外国语学院

DOI:10.32629/er.v2i12.2260

[摘 要] 本文总结了高校近年来信息化建设过程中IT治理工作经验,疑练优势,寻找弱点,结合IT服务的生命周期和信息系统的生命周期,参考 国际上较为流行、通用的IT治理标准核心体系,同时借鉴学校国内相关工作较好高校、企业等相关治理经验,提出针对高校的信息化进行IT治理 的框架方案,并在业内进行有效实践。

[关键词] IT治理；信息化管理；教育信息化

\section{1 中外高校 IT 治理现状概述分析}

在当今信息化快速发展过程中, 强实践性、快速发展以及全面覆盖等 是信息技术所具有的特性, 这便要求需要知技术、会管理、熟业务 (企业里 尤为突出) 的CIO (首席信息官)。这要求CIO要有丰富一线经验, 预防知识老 化, 由此便善于指挥, 亦能谋划。因此在高校的信息化建设过程中, 统筹决 策者与管理者要在管理与技术并重的同时掌握平衡点。

1. 1 国内高校IT治理现状分析 ${ }^{[1]}$

目前, 国内多数高校对于IT治理的概念并不明确, 在信息化建设过 程中更加注重于管理决策与决策划分, 往往忽视了 “IT治理存在一定风 险” 这个更加重要的部分。由高校大数据建设可知, 近年来高校大数据 发展迅速进入白热化, 投入很大, 但成果胗骞。高校的数据虽然规模不大, 但结构复杂, 及难整合。在数据集成的过程中往往费尽九牛二虎之力, 终 于将数据初步集成, 但在准、及、用等方面与理想差距较大。尤其是在 数据抽取集成之后, 如何发布, 之后有何影响? 这都需要高校决策层认 真考虑。

国内多数高校在信息化建设实施过程中, 信息化工作的全局性很强, 很多任务都是跨部门交叉协调, 以往独立存在的信息化部门与其他部门平 级 (很多高校甚至低半级或一级), 开展协调工作的难度比较大。一些经过 调整将信息办挂靠在学校校办, 有一定的改进效果, 协调能力变强, 但受限 于工作性质和工作节奏差异, 效果不甚突出。

经验得知, 实际上信息办 (信息化办公室) 的工作是一条长线, 是业务 逐代不断更迭的过程, 需要长期不断去深入总结。将资源进行最优化配 置, IT能够更好地配合和满足学校治理工作要求, 这便能快速增强高校办 学水平。由此可见IT治理在高校中的十分必要的。

1.2 美国IT治理优秀高校经验分析总结 ${ }^{[1]}$

目前, 经调查, 国内高校信息化机制体制还没有整体规范, 机构设置也 是各不相同。在信息化建设过程中, 总会出现这样那样的问题。美国信息 化建设优秀高校高校中, 主要的制度机制如下:

高校CIO (首席信息官) 制度, 是其运行比较成功的信息化机制之一。这 种制度主要有两种运行机制, 一种是Hub\&Spoke (星型结构), 明确CI0, 并只 设立一个IT管理部门; 另外一种是Paralle1 (并行结构), 不明确指定CIO, 同时设立多个IT管理部门, 分管信息技术、教育技术、图书馆、信息化等

加快建设发展新工科、持续深化工程教育改革, 紧紧围绕国家战略和 区域发展需要, 加快培养适应和引领新一轮科技革命和产业变革的卓越工 程科技人才, 打造工程创新中心和人才高地、探索形成现代化高等工程教 育体系, 必将全面提高我国工程教育人才培养质量、促进我国从工程教育 大国走向工程教育强国, 提升国家硬实力和国际竞争力。
分项项目, 这种结构在麻省理工学院 (IT治理全球排名前列) 、斯坦福大学 (计算机学科排名全球前列) 运行非常成功。

这种制度有两点是值得国内高校学习借鉴:

第一, 这种组织结构都会设立制定战略计划和项目规划的机构, 并能 够实时进行调整。

第二, 所有涉及工作的会议需要全员参与, 掌握全局、运转高校。

在美国高校的这种组织架构中, 领导者 (CIO) 与各类的委员会是决策 层, 没有实体的管理工作机构, 规划和管理等都划分到IT部门的工作职能, 学校IT所涉各界也一起加入进来进行头脑风暴, 加强沟通, 深入需求发掘。

1.3 高校IT治理比较分析研究

众所周知, 美国知名大学的管理水平普遍较高, 美国高校CIO制度职责 单一, 非常值得借鉴。

国内高校IT部门面对的问题是人员不足, 仅能满足正常的最基本的 工作, 谈何高效率、保安全、保服务, 更谈不上谋发展。目前国内高校信 息化工作普遍最大的问题就是人力不足。美国高校普遍的IT工作人员规 模在 $200^{\sim} 400$ 人 (二级单位还有自己单独设置的信息员), 国内高校人员 规模普遍在 $20^{\sim} 30$ 人 (甚至更少)。国内信息化建设领先高校如清华大学、 北京大学、复旦大学等信息化工作人数可能达到百人以上, 但与其学校 规模相比, 还相距甚远。美国一流大学信息化规划的重要内容之一就是 人员团队建设。

国内高校现行通常采取外聘, 外包服务, 转变观念来一定程度上解 决问题, 积累矛盾。应主动培养建立自己的IT工作队伍, 不断壮大, 持续 推进。

由此可知, 国内高校IT治理工作是必要的, 亟待加强, 在该项工作执行 过程中要认清现状, 基于现行国家高校体制, 努力寻找创新点, 持续推进。 高校的IT治理工作需要人才、管理、技术三要素并重。

2 以顶层设计为抓手面向师生服务的高校信息化 ${ }^{[2]}$

高校在事业建设发展的过程中, 对信息化的能力和定位要充满绝对信 心, 不断去进行尝试与实践。以顶层设计为抓手, 加强高校的IT治理工作, 面向师生提供优质的IT服务, 为高校的事业发展不断努力。

2.1 IT治理能够实现高校信息化 “统一建设、统一应用、统一运维” 从高校整体角度看, IT治理有利于整合信息资源, 实现集约建设和资

[参考文献]

[1]林健.引领高等教育改革的新工科建设[J].中国高等教育,2017(Z2):40-43.

[2]重庆邮电大学.多方协同育人创新人才培养体系(14版)[N]. 光明日报,2018-03-16.

[3]百度百科.新工科[Z].https://baike.baidu.com/item/新工科/20597803,2019:8. 
源共享; 从用户角度看, 在IT治理大环境下, 用户无需关注更多, 可以更加 专注于自己的业务发展。

2.2 IT治理可实现信息化业务高可用和自动化

加强高校IT治理, 从用户管理、组织管理、工作流管理、自助Porta1 认证等方面加强工作, 对全校信息化各类资源进行全面而有效的调度和分 配, 同时实现资源的申请、审批到分配部署的智能化、自动化。

2.3 IT治理使得信息化具备良好的扩展支持能力和可持续性

IT治理工作会进行前期各类篮选甄别, 保证信息技术良好的先进性, 以适应未来的发展。采用统一IT管理平台进行信息化管理运维, 对外呈现 统一性, 可持续性。

\section{3 加强 IT 治理才是高校正确的智慧校园建设之道 ${ }^{[3]}$}

在高校今后建设发展过程中, “双一流建设” 是重中之重。学科特色 是双一流建设的重要特点, 而IT治理将在这个过程中扮演着非常重要的角 色, 目前信息技术已经对教学模式、评估模式等产生了巨大的影响。

因此应当加强IT治理, 从观念转变、机制转变等各个环节对信息技术 与教育教学的融合给予更多实践。

3. 1 师生共同参与, 加强高校IT治理

以智能决策、充分互联、全面感知为特点的智慧校园建设, 是未来新 型的学术模式以及特色的行政管理带来的信息化挑战思考, IT治理工作尤 为重要。

智慧校园建设是以人为中心, 对学生对象的全生命周期进行记录, 加 强泛在学习空间建设, 形成信息系统建设对教学科研管理的创新实践, 借 力高校IT治理技术来创新人才培养模式, 改进教学范式, 促进高教变革。

3.2 智慧校园需要 “大智慧”, 更需要IT治理

在智慧校园建设过程中, IT治理应作为手段, 服务于教育教学方式的 变革及人才培养模式的创新, IT治理工作应更加重视如下三个方面:

(1) 智慧校园需要师生共同参与建设。有分析认为, 智慧校园有三个阶 段, 第一个阶段是以信息化为目的, 第二个阶段是以培养创新人才为目的, 第三个阶段则要建立全校信息化生态系统, 加强高校IT治理, 让师生共同 参与建设智慧校园。(2) 流程再造提高师生服务质量, 提高参与度。通过IT 治理工作, 建立标准、规范行为、优化环境、完善手段, 改造和优化现有的 高校服务管理模式, 通过流程再造, 建立网上 “一站式” 服务大厅, 将管理 与服务、监督与协调、规范与引导有效结合, 提高效率。(3) 敏捷校园建设 可提升师生智享生活。加强高校IT治理工作, 加快高校敏捷校园建设。使
得学校师生IT服务全方位提升, 打造无处不在高速、无缝、便捷校园网环 境, 通过敏捷物联校园网将物联网与校园业务有机结合, 实现智慧物联敏 捷校园, 提升管理与服务质量与水平。

3. 3加大全校IT治理统筹力度, 实现统筹、建设、管理 “一盘棋”

进一步学习、贯彻落实国家有关政策, 建设全校上下贯通、运转协调、 便捷高效的比较完整的IT治理体系, 整合利用现有信息化资源, 尽快建成 具有先进水平的信息基础设施, 建成集信息开发、应用、建设、管理与服 务一体化, 坚持 “统筹兼顾、分步实施; 统一平台、资源共享; 统一管理、 加强治理” 的原则, 在高校IT治理的各层面加强统筹, 能实现高校IT治理统 筹、建设、管理 “一盘棋”, 从而提高高校办学水平。

\section{4 结束语}

本文通过对国内外优秀院校的IT治理经验进行研究归纳, 同时总结近 年来国内高校信息化建设管理经验, 分析个中不足, 结合国内外优秀院校 的IT治理经验, 提出一种基于IT治理的信息化管理框架的建设思路, 将信 息化建设过程转变成对IT进行治理的过程, 转变思路, IT管理变为治理, 统 筹全局, 为推动高校信息化快速有效的建设发展做出了贡献, 为教育信息 化的良好提供了IT治理框架研究。

\section{[参考文献]}

[1]张蓓.高校IT治理要基于自身现状[J].中国教育网络,2017(9):49-50.

[2]李学龙,郝文英.基于IT治理的高校校园安全网络框架设计研究与 实现[J].网络安全技术与应用,2017(02):103-104.

[3]教育部.教育部关于印发《教育信息化十年发展规划(2011-2020年)》的 通知[EB/OL].[2019-07-29].http://0ld.moe.gov.cn/publicfiles/ business/ htmlfiles/moe/s5892/201203/133322.htm1.

\section{作者简介:}

郝文英(1985--), 女, 汉族, 山西晋中人, 工学硕士, 教师, 工程师, 研 究方向: 教务教学管理,教学信息化,计算机科学与技术。

李学龙(1986--), 男, 汉族, 内蒙赤峰人, 研究生, 工程师, 从事计算机 科学与技术、网络安全、大数据、高校信息化研究。北京第二外国语 学院网络与信息中心(图书馆)。

\section{基金项目:}

首都对外文化贸易与文化交流协同创新中心 (2011协同创新中 心)(市级)(科研类)项目2018旅游发展基地校级项目,课题编号: C3008180311, 项目负责人: 李学龙。 